\title{
Antischistosomal Activity of Origanum majorana, Ziziphus spina-christi, and Salvia fruticosa Plant Extracts on Hamster Infected with Schistosoma haematobium
}

\author{
Yousef Abdal Jalil Fadladdin (iD) \\ Department of Biological Sciences, Faculty of Sciences, King Abdulaziz University, Jeddah, Saudi Arabia \\ Correspondence should be addressed to Yousef Abdal Jalil Fadladdin; yfadladdin@kau.edu.sa
}

Received 22 February 2021; Revised 3 May 2021; Accepted 5 June 2021; Published 14 June 2021

Academic Editor: Mansour El-Matbouli

Copyright ( 2021 Yousef Abdal Jalil Fadladdin. This is an open access article distributed under the Creative Commons Attribution License, which permits unrestricted use, distribution, and reproduction in any medium, provided the original work is properly cited.

\begin{abstract}
World Health Organization (WHO) has approved only one treatment for schistosomiasis, praziquantel (PZQ), but some poor efficacy was noticed in patients during the early stage of infection. Therefore, researchers have intensified their efforts to research new alternative medicines to treat schistosomiasis. In the present study, in vitro as well as in vivo studies have been accomplished to evaluate the effect of Origanum majorana, Ziziphus spina-christi, and Salvia fruticosa extracts in a different concentration 500, 250, 125, 62.5, and $31.25 \mu \mathrm{g} / \mathrm{ml}$ on golden hamster infected by Egyptian strains of schistosome (Schistosoma haematobium). In vitro, the adult worms and schistosomula of $S$. haematobium were investigated in RPMI-1640 medium for $48 \mathrm{hrs}$. The results showed that the concentration 500, 250, and $125 \mu \mathrm{g} / \mathrm{ml}$ of Origanum majorana, and Ziziphus spina-christi caused dead of $100 \%$ of Egyptian Schistosoma strains of adult worm and schistosomula of S. haematobium within 6 to 12 hrs of incubation. On the other hand, the extract of Salvia fruticosa at concentrations 500, 250, and $125 \mu \mathrm{g} / \mathrm{ml}$ showed death $100 \%$ parasites after 12 to $24 \mathrm{hrs}$ of incubation. Inclusion, Origanum majorana, and Ziziphus spina-christi showed effectiveness against Egyptian Schistosoma strains (S. haematobium), a slight decrease in Salvia fruticosa was observed. Therefore, these medical plant extracts may be used as a safe and effective treatment for schistosomiasis.
\end{abstract}

\section{Introduction}

Schistosomiasis is a worldwide disease, and it is sometimes called bilharzia. The intermediate host is the freshwater snail that transmits intravascular weakening disease resulting from infection with one of the types of Schistosoma that lives within the human vascular system, which lives within the circulation system of people $[1,2]$. The World Health Organization Special Program for Research and Preparing in Tropical Diseases has classified schistosomiasis into the second category after malaria in significance as a targeted tropical disease. The World Health Organization (WHO) has considered schistosomiasis to be a tropical disease that has been neglected. All over the world, in known transmission ranges, about 732 million people have been assessed as being defenseless to the disease [3].
There are two major shapes of schistosomiasis: the intestinal (caused by four species called Schistosoma mansoni (S. mansoni, S. japonicum, S. mekongi, and S. intercalatum) and the urogenital caused by (S. haematobium) [4].

$S$. haematobium was a chronic disease in old Egypt. Ruffer in 1910 was the first to diagnosis S. haematobium contaminations in mummies. He recouped calcified schistosome eggs from two Egyptian mummies of the $20^{\text {th }}$ Dynasty [5]. The radiological examination too unequivocally recommended that the calcified bladder in two other mummies were due to $S$. haematobium contamination [6, 7]. Also, in 1937, the primary schistosomiasis epidemiological studies were conducted over Egypt. S. haematobium was found as it were in Upper Egypt, which compares geographically to the southern portion of Egypt. Cases were restricted to districts with a perpetual water system, agricultural systems in the area [8]. Then, Barakat [9] found that in zones utilizing 
the perpetual water systems, both within the Nile Delta and Vile Valley south of Cairo, an average of $60 \%$ predominance rate of S. haematobium infection was evaluated. In contrast, those areas that utilized basin water systems had an assessed $6 \%$ predominance. The allocation of S. haematobium hence appeared a clear relationship to the improvement of irrigation plan that permitted for year circular standing water, increased human-water contact, and get better snail habitat. The predominance of S. mansoni was evaluated at $60 \%$ prevalence within the Northern and Eastern parts of the Nile Delta and only $6 \%$ predominance within the Nile Valley locale overviewed [9].

Side effects of schistosomiasis were caused by the body response to the eggs of schistosome. Haematuria (blood in urine) appears as a classical indicator of urogenital schistosomiasis. Fibrosis of the ureter and bladder and kidney harm is in some cases diagnosed in progressed cases. Cancer of the bladder is another conceived complexity within the last stages. In ladies, urogenital schistosomiasis might current with genital injuries, nodules in the vulva, suffering in sexual intercourse, and vaginal bleeding. In man, schistosomiasis may also be associated with the urogenital system, diseases of the prostate, seminal vesicles, and other organs. In the long term, this disease may also have other irreversible outcomes, including infertility [4].

Until the 1970s, the treatment of schistosomiasis was complicated and nearly poisonous until praziquantel was discovered $[10,11]$. In 1988, the World Health Organization approved the praziquantel as a treatment and control of schistosomiasis [11]. Though praziquantel is considered safe and successful against all Schistosoma species [12] and has been used in the last 32 years, it is considered a long period for a single drug for the parasite; the drug is not free of troubles. For occurrence, the enormous and elite utilize of praziquantel for numerous decades as a sole medicate has clearly raised legal fears that schistosomes maybe become resistant to praziquantel sooner or afterward show up [12]. Moreover, praziquantel works successfully against adult worms of schistosomes, but it is inactive against other stages of schistosomes, such as schistosomula, preadults, and juvenile adults. As a result, the recurrence of the drug for some time is essential to murder those parasites that have since developed. In addition, having a single medicate to treat an illness that influences millions of individuals in numerous geographical ranges may be a genuine concern. Subsequently, it is urgent to improve unused successful and secure antischistosomal drugs. The advancement of antischistosomal mechanisms from natural sources has become a critical requirement in recent years. Medicinal plants have been a natural source of medicines for thousands of years [13]. The medicinal plant has been utilized as natural sources for the discovery of unused medicates. The scientific assessment of therapeutic plants utilized within the planning of people treatment has given present-day pharmaceutical with successful pharmaceuticals for the treatment of infections caused by parasites. Several natural extracts or compounds have been distinguished from plants with promising antischistosomal properties [14-21]. In this setting, the medicinal plants and compounds derived from these plants acquire an unmistakable quality as conceivable sources of modern drugs within the treatment and control of schistosomiasis.

The present research aimed to evaluate the aqueous extracts of Origanum majorana, Ziziphus spina-christi, and Salvia fruticosa against Egyptian strain of schistosome (Schistosoma haematobium) in the laboratory as well as in the experimental animals.

\section{Materials and Methods}

2.1. Plant Materials. The leaves of Origanum majorana, Ziziphus spina-christi, and Salvia fruticosa were obtained, which were washed well to prevent the loss of active ingredients. They were dried in the shade and avoided exposure to sunlight as they were identified by the Department of Horticulture, Faculty of Agriculture, Ain Shams University.

2.2. Aqueous Extract Preparation. The extraction of Origanum majorana, Ziziphus spina-christi, and Salvia fruticosa leaves was prepared according to Ekpo and Etim [22]; by an electric grinder, the dried plant leaves were ground to fine powders. In two liters of distilled water, the ground leaves weighing $200(\mathrm{~g})$ were extracted $(1: 10 \mathrm{w} / \mathrm{v})$ by cold extraction and evaporation of the extract in vacuo. Using a rotary evaporator at $40^{\circ} \mathrm{C}$, the extract was concentrated in vacuo. Finally, the extract was placed in porcelain dishes in a temperature-controlled oven to remove the remaining water from the extract and to get a residue. The residue of the three plant extracts was approximately $8.5 \mathrm{~g}$ for each extract. The extracts at $4^{\circ} \mathrm{C}$ were stored for use later [22].

2.3. Toxicological Study. To measure the maximum nontoxic concentration (MNTC), Serial dilutions of $10-300 \mu \mathrm{g} / \mathrm{ml}$ of the plant extracts onto Vero cells according to Mosmann technique [23] were applied. When the aqueous extract is diluted in a manner that preserves the normal shape of the tested Vero cells as well as their density, by comparing them with untreated control cells, at least $95 \%$ of the optical density is the MNTC value.

\subsection{Experimental Design}

2.4.1. Infection of the Hamster with Schistosoma Cercariae. Hamsters were ready at the start of the biological experiment (Week 0), thus losing consciousness and suppressing muscle relaxation and reflex activity with general anesthesia for the hamster. To provide a combined effect for anesthesia, a volume-based ratio 3:1 ketamine and Rompun was used. Intraperitoneally, the dose of anesthesia was injected $0.02 \mathrm{ml} / 30 \mathrm{~g}$ of the animal's body weight. The hamster was arranged on a wooden shelf after the animal was shaved from the stomach area. To allow easy penetration of the infected stage (cercariae), cotton wool was dipped in water and was used to moisten the shaven area. On each hamster, a metal ring of $1 \mathrm{~cm}$ was placed on the shaven area of hamster; then, using a micropipette, a suspension containing around 250 live infective stage (cercariae) was placed in the metal ring for 30 minutes to give allowance to the cercariae it to penetrate the hamster [24]. 
2.5. Parasite. Pairs of Egyptian strains of schistosomes adult worms (S. haematobium) were obtained from sacrificed infected hamster by perfusion of the mesenteric veins and hepatic portal system of their livers using citrated saline after three months of postinfection according to Stirewalt and Dorsey technique [25].

2.6. In Vitro Study. Perfusion worms were washed three times with the RPMI 1640 (BioWhittaker ${ }^{\circledR}$ ) culture medium (Lonza, B-4800 Verviers, Belgium), which was used for culturing the parasite. $20 \%$ fetal calf serum, antibiotics, and L-glutamine (300 IU penicillin, $160 \mu \mathrm{g}$ gentamycin per $\mathrm{ml}$ and, $300 \mu \mathrm{g}$ streptomycin) were used as supplements for the medium [26]. After the washing, in each well of a 24-well culture plate, 7 couples of worms were transferred (TPP, St. Louis, MO) having one (ml) of the RPMI 1640 medium. One (ml) of the concentrations (500, 250, 125, 62.5, and $31.25 \mu \mathrm{g} / \mathrm{ml}$ ) from each examined aqueous plant extract were added. The final volume was $2(\mathrm{ml})$ in each well. The plate in a humid atmosphere containing $5 \% \mathrm{CO}_{2}$ at $37^{\circ} \mathrm{C}$ was incubated (Thermo Fisher Scientific, Marietta, OH, USA) [27]. The parasite was kept for $48 \mathrm{~h} .10 \mu \mathrm{g} / \mathrm{ml}$ of PZQ used as a positive control, while a medium with pure medium and sterile distilled water were used as negative controls. Under a sterilized laminar flow chamber, all previous steps were performed. The trial was carried out in repeated and triplicate 3 times. An inverted optical microscope (Olympus CK2) was used to monitor the treated worms' mating (pairing), motility rate (activity changes of worm's motor), and mortality. Worms that did not show motility for two minutes were considered dead. Changes in worm's motor activity (motility) of schistosomes were assessed qualitatively and decreased motor activity was defined as "significant" or "slight" [28]. The adult schistosomes and their schistosomula observation was performed, throughout the $48 \mathrm{~h}$, experimental incubation period, and the results were recorded at 2, 4, 6, 12,24 , and $48 \mathrm{~h}$ (trial endpoint for the negative control groups).

2.7. Electron Microscope. To observe the morphological changes that occur in the tegument of adult worms in both male and female after being exposed to plant extracts at different concentrations, they were prepared for examination by Scanning Electron Microscope (SEM) according to Glauert technique [29].

\subsection{In Vivo Study}

2.8.1. Animals. A total of twenty-six adult golden hamsters weighing 105-130 g infected with Schistosoma haematobium were maintained and kept separately in a cage prepared for the examination of fecal materials for obtaining parasites in the study. The infected animals were randomly divided into 6 groups with 5 animals each; at the time of the experiment, the route of administration was orally for all treatments:

(G1) Uninfected golden hamster (Healthy control).

(G2) Infected golden hamster with adult S. haematobium and schistosomula given distill water (negative control).
(G3) Infected golden hamster with adult S. haematobium and schistosomula treated with $200 \mathrm{mg} / \mathrm{kg}$ PZQ (positive control).

(G4) Infected golden hamster with adult S. haematobium and schistosomula treated with $600 \mathrm{mg} / \mathrm{kg}$ Origanum majorana.

(G5) Infected golden hamster with adult S. haematobium and schistosomula treated with $600 \mathrm{mg} / \mathrm{kg}$ Ziziphus spinachristi.

(G6) Infected golden hamster with adult S. haematobium and schistosomula treated with $800 \mathrm{mg} / \mathrm{kg}$ Salvia fruticosa.

2.9. Histopathological Assessment. After dosing, the hamsters were slaughtered to obtain the liver, spleen, and kidney and were stored in $10 \%$ formalin for at least two weeks. Small portions of the organs were obtained and washed overnight under running water to remove excess formalin. Slices were made to be examined microscopically for granulomas according to Baker [30] and Farah [31].

2.10. Identification of Most Potent Plant Extract. Identification of antischistosomal activity of three plants: Origanum majorana, Ziziphus spina-christi, and Salvia fruticosa evaluated at specialized Regional Center for Mycology and Biotechnology (RCMB) by extraction method, and absorbance of oil solutions in methanol measured with UV-240 spectrophotometer (Schimmadzu-Corporation, Kyoto, Japan). By the maceration method, the plant extract was prepared. The appropriate solvent has been selected to make the maceration with stirring or several times shaking at room temperature [32].

2.11. Gas Chromatography-Mass Spectrometry (GC-MS) Analysis. Extract components were identified using a Trace GC1310-ISQ mass spectrometer (Thermo Scientific, Austin, TX, USA) with a TG-5MS direct capillary column $(30 \mathrm{~m} \times$ $0.25 \mathrm{~mm} \times 0.25 \mu \mathrm{m}$ thickness film). The temperature of the oven column started at $50^{\circ} \mathrm{C}$ and was raised by $5^{\circ} \mathrm{C} / \mathrm{min}$ until it reached $230^{\circ} \mathrm{C}$ and held for $2 \mathrm{~min}$. It was raised by $30^{\circ} \mathrm{C} / \mathrm{min}$ until reached $290^{\circ} \mathrm{C}$ and held for $2 \mathrm{~min}$, which is the final temperature. The injector was kept at $250^{\circ} \mathrm{C}$ and MS transfer line temperature at $260^{\circ} \mathrm{C}$. At a constant flow rate of $1 \mathrm{ml} / \mathrm{min}$, use helium gas as the carrier gas. The solvent delay was $3 \mathrm{~min}$, and $1 \mu \mathrm{l}$ of diluted samples were injected automatically by AS1300 Autosampler connected to the GC. In full scan mode, EI mass spectra was aggregated at $70 \mathrm{eV}$ ionization voltage over the range of $\mathrm{m} / z$ 40-1000. The ion source temperature was fixed at $200^{\circ} \mathrm{C}$. The active component was determined by comparing the mass spectra and retention time with those of NIST 11 and WILEY 09 mass spectral database.

2.12. Statistical Analysis. To analyze the collected data, the Statistical program (SPSS) for windows version 25.0 was used. Normality tests have been used to determine whether a particular set of data was normally distributed. The Shapiro Wilk test was used to check the normal distribution [33]. Moreover, all data were presented quantitatively. Groups were compared using one-way ANOVA to compare of 


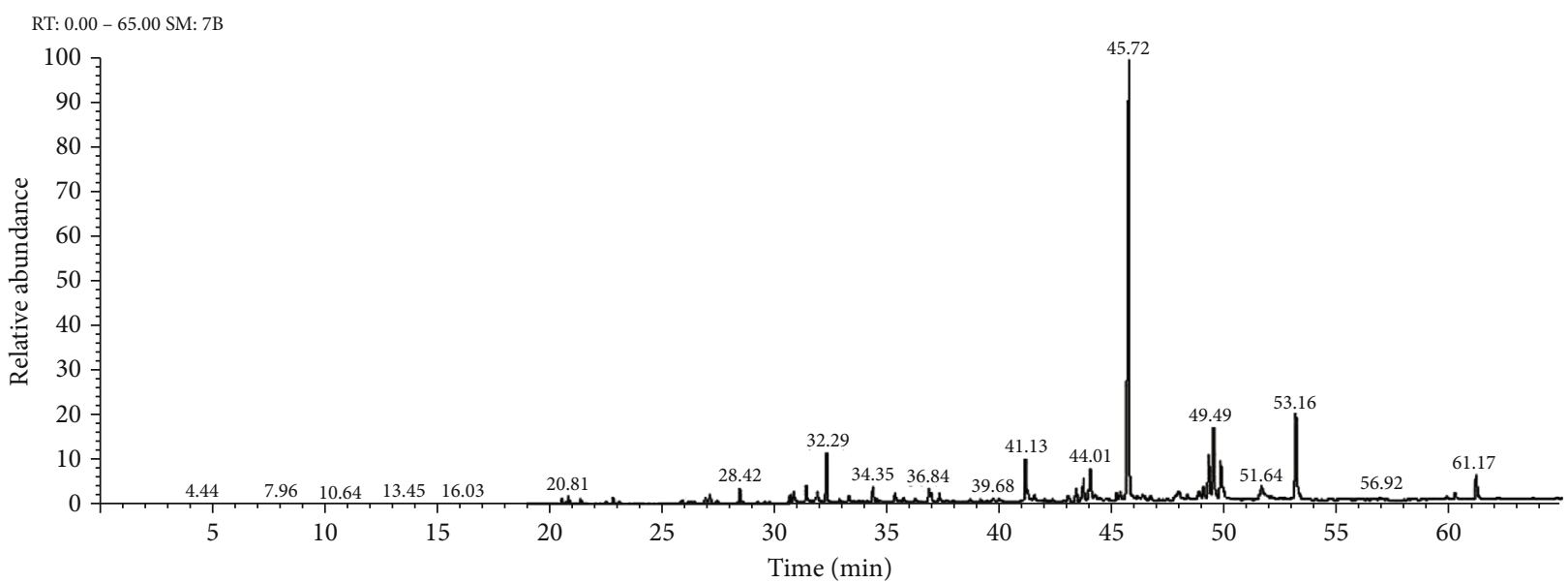

FIGURE 1: GC-MS chromatogram of aqueous extract of Origanum majorana.

TABLE 1: Identified compounds in aqueous extract of Origanum majorana.

\begin{tabular}{|c|c|c|c|c|c|c|}
\hline No. & RT & M. wt & M. formula & Prediction & Area & Area \% \\
\hline 1 & 20.52 & 204 & $\mathrm{C}_{15} \mathrm{H}_{24}$ & Zingiberene & 54727666.55 & 0.36 \\
\hline 2 & 20.80 & 222 & $\mathrm{C}_{15} \mathrm{H}_{26} \mathrm{O}$ & Nerolidol & 79653206.07 & 0.52 \\
\hline 3 & 26.89 & 222 & $\mathrm{C}_{15} \mathrm{H}_{26} \mathrm{O}$ & Cubenol & 90321047.45 & 0.59 \\
\hline 4 & 26.89 & 222 & $\mathrm{C}_{15} \mathrm{H}_{26} \mathrm{O}$ & Eudesmenol & 118361109.56 & 0.78 \\
\hline 5 & 28.42 & 220 & $\mathrm{C}_{15} \mathrm{H}_{24} \mathrm{O}$ & Cedren & 176248647.53 & 1.16 \\
\hline 6 & 30.66 & 30.66 & $\mathrm{C}_{15} \mathrm{H}_{22} \mathrm{O}$ & Phenol & 98240348.64 & 0.65 \\
\hline 7 & 30.81 & 30.81 & $\mathrm{C}_{11} \mathrm{H}_{14} \mathrm{O}_{3}$ & Butanone & 163365217.48 & 1.08 \\
\hline 8 & 33.26 & 222 & $\mathrm{C}_{15} \mathrm{H}_{26} \mathrm{O}$ & Eudesmol & 106173887.45 & 0.70 \\
\hline 9 & 36.84 & 188 & $\mathrm{C}_{9} \mathrm{H}_{16} \mathrm{O}_{4}$ & Propanol & 164765320.50 & 1.08 \\
\hline 10 & 45.71 & 276 & $\mathrm{C}_{17} \mathrm{H}_{24} \mathrm{O}_{3}$ & Gingerol & 6205744296.17 & 40.86 \\
\hline 11 & 47.93 & 200 & $\mathrm{C}_{6} \mathrm{H}_{9} \mathrm{FN}_{6 \mathrm{O}}$ & Capsaicin & 274275241.47 & 1.81 \\
\hline 12 & 48.83 & 292 & $\mathrm{C}_{21} \mathrm{H}_{4} 0$ & Nonivamide & 151523642.98 & 1.00 \\
\hline 13 & 60.25 & 412 & $\mathrm{C}_{29} \mathrm{H}_{48} \mathrm{O}$ & Stigmasterol & 92898328.92 & 0.61 \\
\hline 14 & 61.17 & 414 & $\mathrm{C}_{29} \mathrm{H}_{50} \mathrm{O}$ & á-Sitosterol & 351889991.52 & 2.32 \\
\hline
\end{tabular}

quantitative data of more than two groups for parametric data. The $p$ value $<0.05$ was considered statistically significant.

\section{Results}

3.1. Cytotoxicity. When treating Vero cells with a maximum dose of nontoxicity (MNTD) for the tested plant extracts (Origanum majorana, Ziziphus spina-christi, and, Salvia fruticosa) of 250,300 , and $350 \mu \mathrm{l} / \mathrm{ml}$, respectively, no morphological differences were shown compared to the control group.

3.2. Phytochemistry. Sweet marjoram (Origanum majorana) is characterized by a pleasant odor and flavor and a strong spicy. The chemical compositions of the important oils acquired from O. majorana (Figure 1) are listed in Table 1.

On the other hand, the chemical compositions of the important oils acquired from Ziziphus spina-christi (L.) (Figure 2) are recorded in Table 2.
The chemical compositions of the important oils acquired from Salvia fruticosa are recorded in Table 3 (Figure 3).

3.3. Antischistosomal Activity. In laboratory treatment effectiveness of Origanum majorana, Ziziphus spina-christi, and Salvia fruticosa extracts on adults of S. haematobium at diverse concentrations as studied, natural mating was affected by all the experimental extracts, these causing disconnections of couple Schistosoma relying on the concentration utilized and exposure period. About $90 \%$ of the parasites has been disconnected in the first two hours with the utilize of $500,250 \mu \mathrm{g} / \mathrm{ml}, \sim 80 \%$ of parasites had been detached within $4 \mathrm{~h}$ with the dose of $125,62.5 \mu \mathrm{g} / \mathrm{ml}$, and in a lower concentration of $31.25 \mu \mathrm{g} / \mathrm{ml}$, the detached was $65 \%$ after $12 \mathrm{~h}$ of Origanum majorana and Ziziphus spina-christi. While the Salvia fruticosa showed less effect than Origanum majorana and Ziziphus spina-christi which the detached showed after $6 \mathrm{~h}(65 \%)$ at the highest concentration. $10 \mu \mathrm{g} / \mathrm{ml}$ Praziquantel after the first $2 \mathrm{~h}$ of incubation caused 


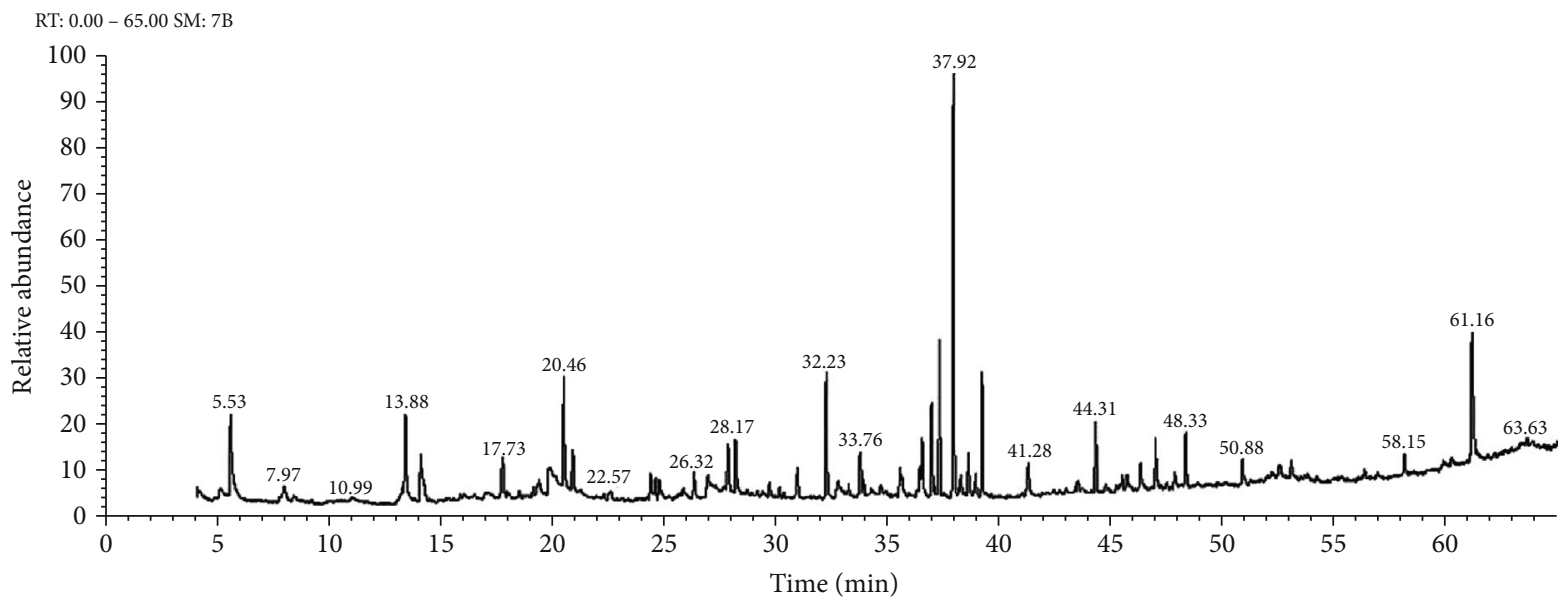

FIGURE 2: GC-MS chromatogram of aqueous plant extract of Ziziphus spina-christi.

TABLE 2: Identified compounds in aqueous extract of Ziziphus spina-christi (L.).

\begin{tabular}{|c|c|c|c|c|c|c|}
\hline No. & $\mathrm{RT}$ & MW & M. formula & Identified compounds & Chromatogram area & Chromatogram area $\%$ \\
\hline 1 & 13.23 & 615 & $\mathrm{C} 23 \mathrm{H} 45 \mathrm{~N} 5 \mathrm{O} 14$ & D-Streptamine & 8421115.74 & 0.48 \\
\hline 2 & & 154 & $\mathrm{C} 10 \mathrm{H} 18 \mathrm{O}$ & p-Menthadiene & & \\
\hline 3 & 17.73 & 592 & $\mathrm{C} 16 \mathrm{H} 48 \mathrm{O} 8 \mathrm{Si} 8$ & Cyclooctasiloxane & 36726047.85 & 2.11 \\
\hline 4 & 19.82 & 110 & $\mathrm{C} 6 \mathrm{H} 6 \mathrm{O} 2$ & Hydrochinon & 54912618.86 & 3.15 \\
\hline 5 & 20.47 & 145 & $\mathrm{C} 8 \mathrm{H} 7 \mathrm{~N} 3$ & Benzene & 70108424.28 & 4.02 \\
\hline 6 & 20.89 & 458 & $\mathrm{C} 28 \mathrm{H} 30 \mathrm{~N} 2 \mathrm{O} 4$ & Morphinan & 28332599.99 & 1.62 \\
\hline 7 & 24.58 & 220 & $\mathrm{C} 15 \mathrm{H} 24 \mathrm{O}$ & Tricycloundecan & 16114395.18 & 0.92 \\
\hline 8 & 24.58 & 220 & $\mathrm{C} 15 \mathrm{H} 24 \mathrm{O}$ & Spathulenol & 16114395.18 & 0.92 \\
\hline 9 & 24.76 & 153 & $\mathrm{C} 6 \mathrm{H} 7 \mathrm{~N} 3 \mathrm{O} 2$ & Imidazole & 19324582.43 & 1.11 \\
\hline 10 & 26.32 & 190 & $\mathrm{C} 13 \mathrm{H} 18 \mathrm{O}$ & Megastigmatrienone & 17929010.41 & 1.01 \\
\hline 11 & 26.93 & 283 & $\mathrm{C} 10 \mathrm{H} 13 \mathrm{~N} 5 \mathrm{O} 5$ & Guanosine & 22821026.68 & 1.31 \\
\hline 12 & 32.76 & 279 & $\mathrm{C} 10 \mathrm{H} 17 \mathrm{NO} 6 \mathrm{~S}$ & Desulphosinigrin & 20218112.12 & 1.16 \\
\hline 13 & 41.28 & 519 & $\mathrm{C} 30 \mathrm{H} 53 \mathrm{NO} 4 \mathrm{Si}$ & Glycine & 28017325.31 & 1.61 \\
\hline 14 & 46.99 & 286 & $\mathrm{C} 20 \mathrm{H} 30 \mathrm{O}$ & Phenanthrenemethanol & 33473432.07 & 1.92 \\
\hline 15 & 53.07 & 439 & $\mathrm{C} 31 \mathrm{H} 21 \mathrm{NS}$ & Thienopyridine & 14058118.79 & 0.81 \\
\hline 16 & 61.17 & 414 & $\mathrm{C} 29 \mathrm{H} 50 \mathrm{O}$ & á-Sitosterol & 98265259.33 & 5.63 \\
\hline
\end{tabular}

TABLe 3: Identified compounds in aqueous extract of Salvia fruticosa.

\begin{tabular}{|c|c|c|c|c|c|c|}
\hline No. & RT & MW & M. formula & Identified compounds & Chromatogram area & Chromatogram area $\%$ \\
\hline 1 & 10.43 & 341 & $\mathrm{C} 20 \mathrm{H} 23 \mathrm{NO} 4$ & Quinolinol & 3053550.06 & 3.26 \\
\hline 2 & 14.16 & 576 & C18H52O7Si7 & Tetrasiloxane & 3831389.13 & 4.08 \\
\hline 3 & 20.88 & 428 & $\mathrm{C} 27 \mathrm{H} 44 \mathrm{O} 2 \mathrm{Si}$ & Androstadienol & 2861964.11 & 3.05 \\
\hline 4 & 22.53 & 283 & $\mathrm{C} 10 \mathrm{H} 13 \mathrm{~N} 5 \mathrm{O} 5$ & Purinol & 1584222.84 & 1.69 \\
\hline 5 & 30.94 & 428 & $\mathrm{C} 27 \mathrm{H} 40 \mathrm{O} 4$ & Spirosten & 1522237.77 & 1.62 \\
\hline 6 & 32.36 & 256 & $\mathrm{C} 16 \mathrm{H} 32 \mathrm{O} 2$ & Tetradecanoic acid & 12521180.76 & 13.35 \\
\hline 7 & 35.11 & 195 & C11H17NO2 & Benzenemethanol & 4860449.32 & 5.18 \\
\hline 8 & 36.42 & 366 & $\mathrm{C} 13 \mathrm{H} 30 \mathrm{~N} 2 \mathrm{O} 4 \mathrm{SSi} 2$ & Cystathionine & 1306854.22 & 1.39 \\
\hline 9 & 49.30 & 514 & $\mathrm{C} 27 \mathrm{H} 31 \mathrm{BrO} 5$ & Terphenyl & 2374908.89 & 2.53 \\
\hline
\end{tabular}

separation in a pair of worms. Whereas, negative control groups were observed to separate couples after 12 hours of incubation. In contrast, concentrations that were not lethal to the parasites at $100 \%$ were an effective inhibitor of malefemale couples, so upon completion of the incubation, there were no couples between the worms. 


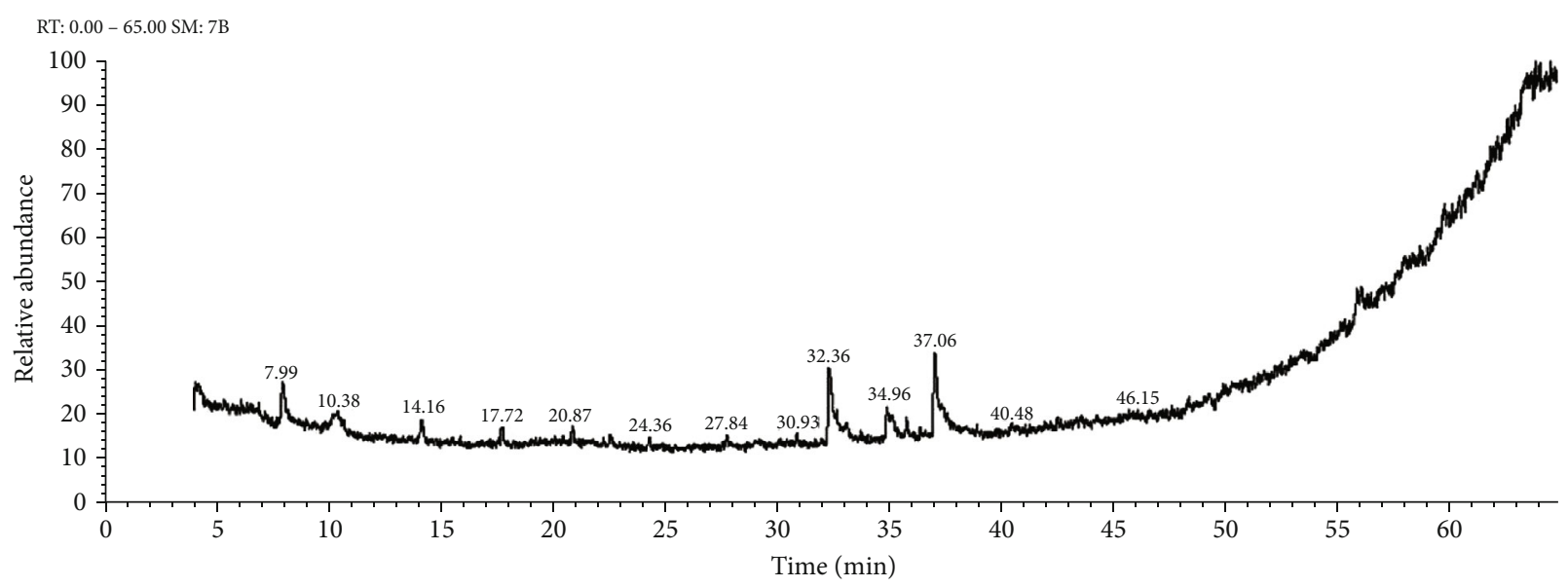

FIgURE 3: GC-MS chromatogram of aqueous plant extract of Salvia fruticosa.
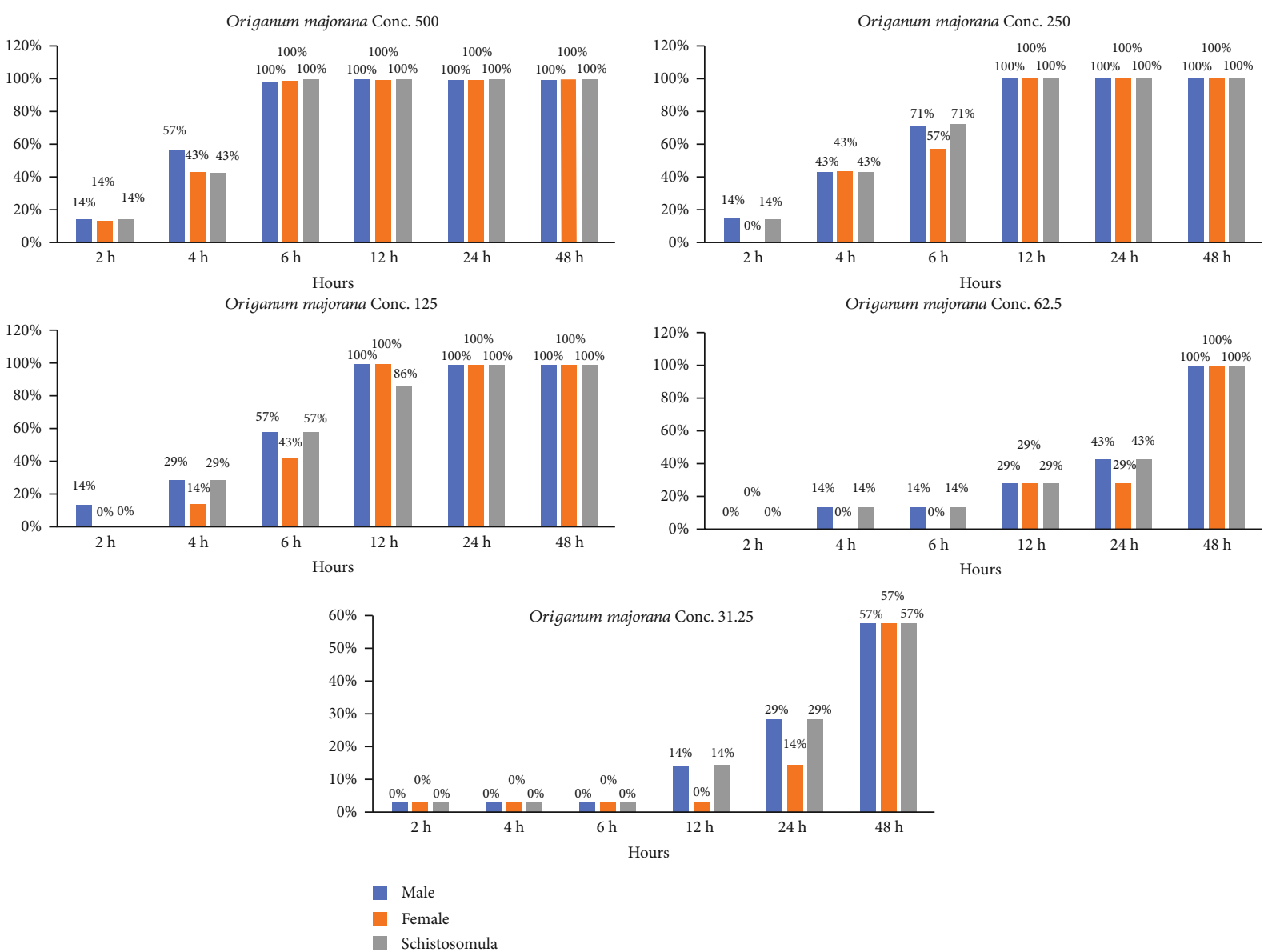

FIGURE 4: Statistical outcome of the effectiveness of Origanum majorana with different times and different concentrations on S. haematobium.

About the movement, at most concentrations, a noteworthy decrease was observed within the worm motility. The concentration of the extracts and the incubation time were directly related to the movement of the parasite as they were the main factor in decreasing the percentage of movement among the Schistosoma worms, after two hours of incubation; the movement activity of all adult worms was moni- tored, after exposure to concentrations of 500, 250, and $125 \mu \mathrm{g} / \mathrm{ml}$ of both Origanum majorana and Ziziphus spinachristi begins to decline slightly. Whereas, the movement of adult worms began to decline after 12 hours without apparent loss of movement when exposed to concentrations of 62.5 and $31.25 \mu \mathrm{g} / \mathrm{ml}$. While the Salvia fruticosa showed less effect than Origanum majorana and Ziziphus spina-christi 

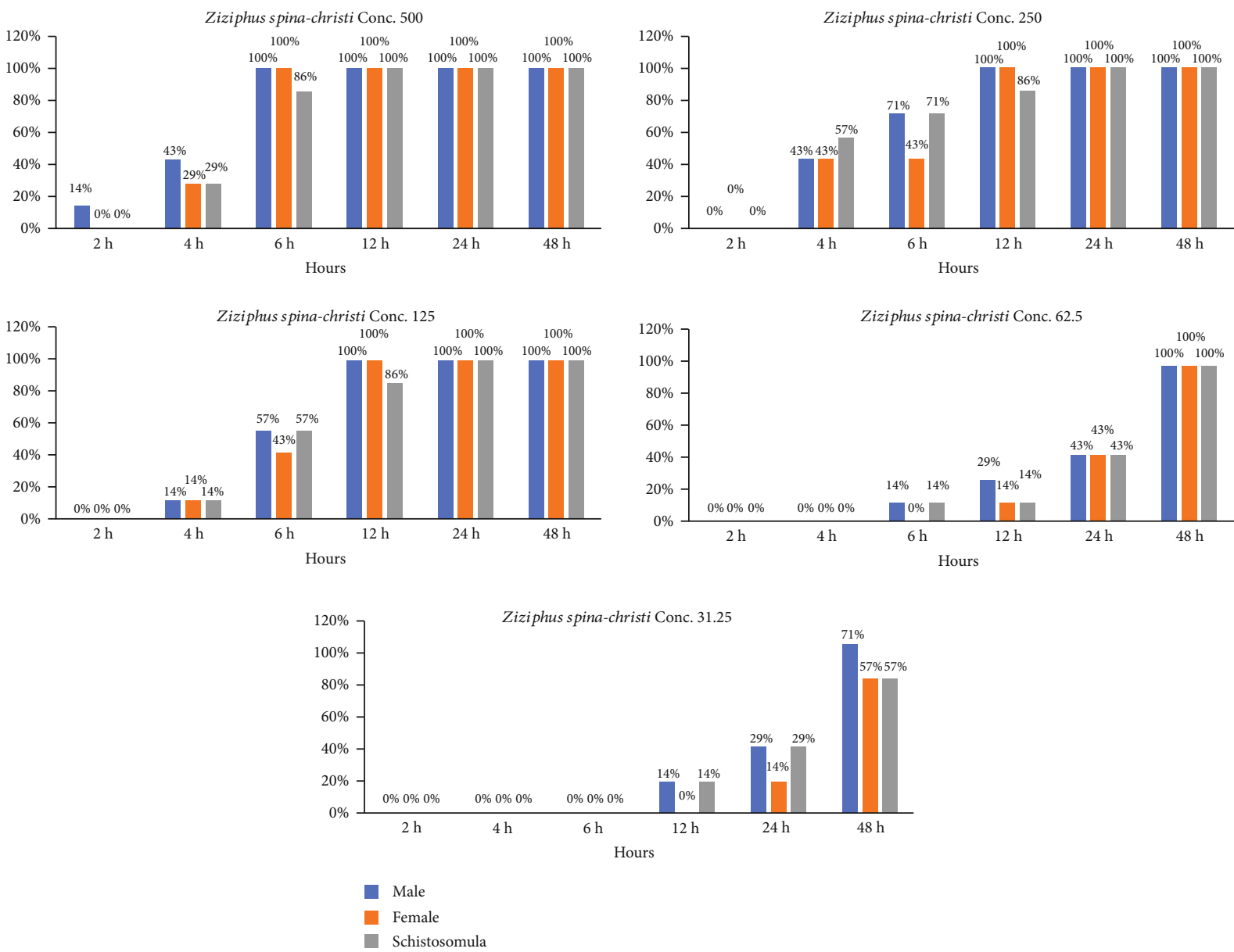

Figure 5: Statistical outcome of the effectiveness of Ziziphus spina-christi with different times and different concentrations on S. haematobium.

which reduced the movement appearance after $12 \mathrm{~h}$ at high concentration. Movement activity was watched at a $24 \mathrm{~h}$ period with no change, in negative control groups. Whereas it reduced at a 48 -h period but not total lack of motility happened. Furthermore, after the first $2 \mathrm{~h}$ of incubation of the Schistosoma with $10 \mu \mathrm{g} / \mathrm{ml}$ of PZQ led to a reduction in motility activity, and the total lack of activity occurred in all worms at a $4 \mathrm{~h}$ period.

The current result showed that the existence of $S$. haematobium adult parasites and schistosomula exposed to aqueous extracts of Origanum majorana, Ziziphus spinachristi, and Salvia fruticosa depended immediately on both the incubation time and concentrations. The dose of 500, 250, and $125 \mu \mathrm{g} / \mathrm{ml}$ of Origanum majorana and Ziziphus spina-christi caused the death of $100 \%$ of schistosomule and adult worms within six and twelve hours of incubation, respectively (Figures 4 and 5). Though, the concentrations of 500,250 , and $125 \mu \mathrm{g} / \mathrm{ml}$ of aqueous extract of Salvia fruticosa resulted dead of $100 \%$ parasites after twelve to twenty-four hours of incubation, respectively (Figure 6). Origanum majorana and Ziziphus spina-christi $(500 \mu \mathrm{g} / \mathrm{ml})$ lead to critical kill rate $(p<0.001)$ between Schistosoma parasites after six hours of incubation, while at 250 and $125 \mu \mathrm{g} / \mathrm{ml}$ concentration of the Origanum majorana and Ziziphus spina-christi extracts expressed their kill-rate effect on adults $S$. haematobium after eight and twelve hours of incubation, respectively (Figures 4 and 5). The current result showed the adult male and female worms had a reaction with the different concentrations of the aqueous extracts used in the mortality rate or existence rates, as the results showed.

Whereas, the effect of PQZ on positive groups was 100\% complete death of worms after four hours of incubation. In contrast, untreated worms lived up to 48 hours of incubation and they were the negative groups; the experiment ended at this stage.

3.4. Scanning Electron Microscope (SEM) Examination. The body wall of adult worms for Schistosoma haematobium was studied by scanning electron microscopy, obtained from untreated golden hamsters; in the male, the ventral canal called the gynaecophoric and the dorsal surface of the worms were characterized by the presence of many large spiny tubercles, but the areas between these tubercles have no spines; on the other hand, the abdominal surface was supported by lines of small spines. The ventral sucker appeared in a round shape and was covered with spines, while the oral sucker was oval in shape and strengthened with different 

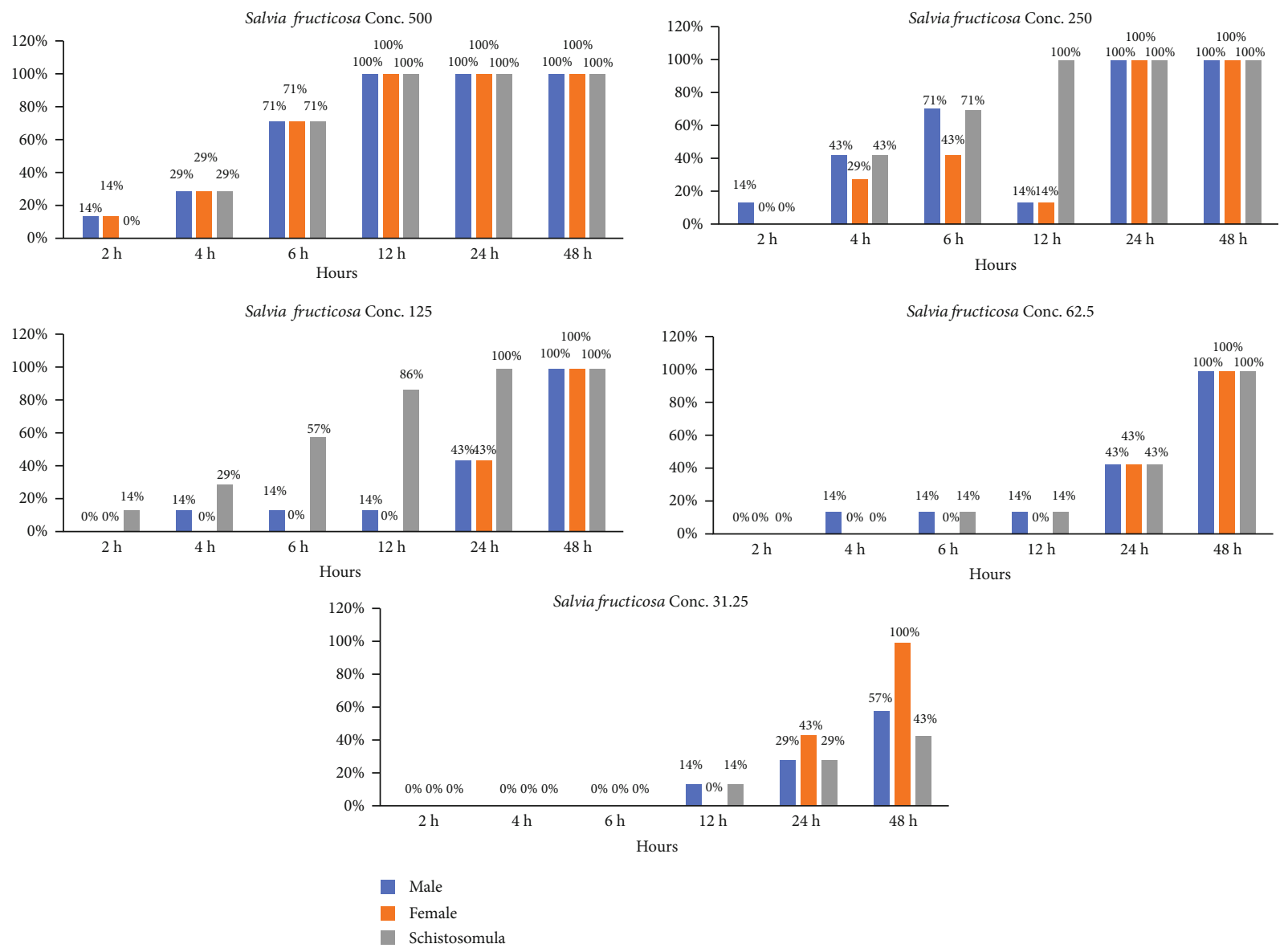

Figure 6: Statistical outcome of the effectiveness of Salvia fruticosa with different times and different concentrations on S. haematobium.

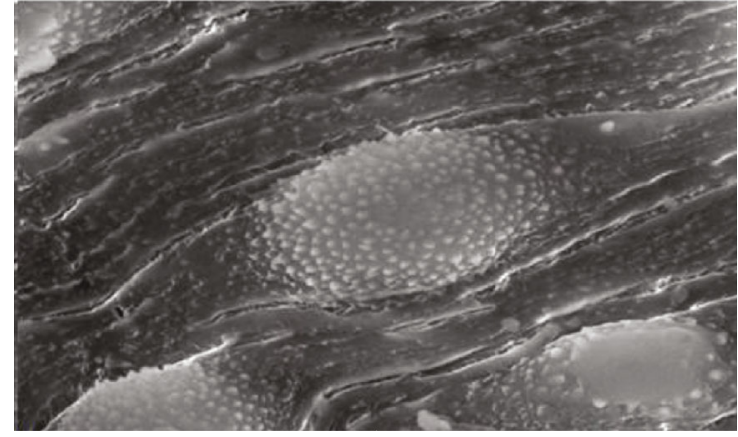

Figure 7: Normal tegument of $S$. haematobium from the hamster tissue.

sizes of sharp spines. Tubercles were surrounded by wrinkled tegument (Figure 7).

After treating the golden hamster with aqueous extracts of Origanum majorana, Ziziphus spina-christi, and Salvia fruticosa, significant tegumental changes appeared in the adult worms of $S$. haematobium and schistosomule. Similarly, after incubating male and female Schistosoma for 48 hours in the laboratory at concentrations of $500 \%$, $250 \%, 125 \%, 62.5 \%$, and $31.25 \%$ of plant extracts, ultramorphological differences were observed in adult worms of males and females, with more harmful effects on males.

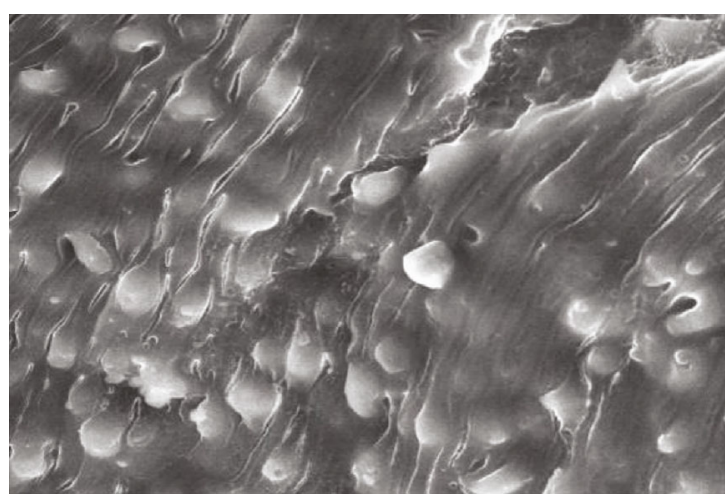

FIgURE 8: Effect PZQ on adult worms of Schistosoma.

When comparing the worms exposed to Origanum majorana, Ziziphus spina-christi with the untreated group revealed a varying degree of morphological changes. Whereas, the worms that were treated with PQZ revealed a change in the tegument of the worms by $100 \%$, which showed a similarity between the effect of the extracts and the positive control (Figure 8).

Male Schistosoma had shown clear morphological changes, especially on the dorsal surface, with the appearance of deformations in the tubercles and the decay of the spines (tegument sloughing or peeling, peeling of tubercles, spines, 


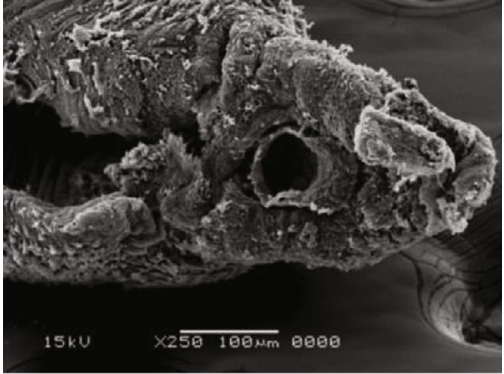

(a)

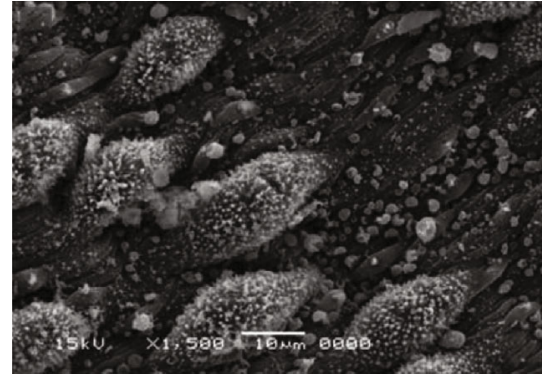

(b)

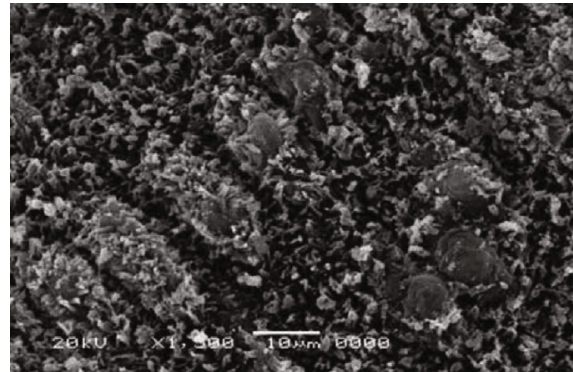

(c)

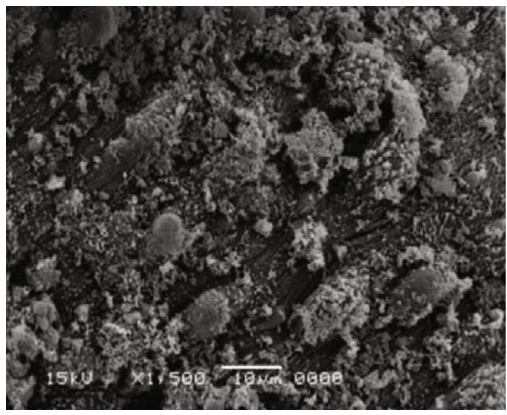

(d)

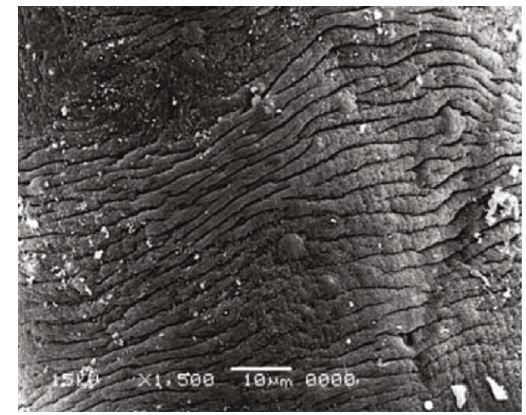

(e)

FIGURE 9: Scanning electron microscopy of S. haematobium (adult worms and schistosomula) after exposure to different concentrations of Origanum majorana. (a) Destroyed sucker. (b, c, d) Dorsal surface of male showing tegumental exfoliation with damage and exfoliation of spines and tubercles. (e) Schistosomula.

devastation). Changing or destroying the suckers was observed, where the oral sucking of some worms was deformed, and small bubbles with variable numbers appeared around the morphologically modified tubercles. Whereas in females, the effect was less due to the absence of tubercles or spines, so wrinkles, erosion, and peeling (contraction and peeling of the dorsal surface) were observed, as well as the destruction of suckers or a change in their shape (Figures 9 and 10).

In connection with Salvia fruticosa extract, the worms (adult worms male and female, schistosomule) emerged comparable morphological tegumental changes but with a lower degree to Origanum majorana and Ziziphus spinachristi stimulate morphological changes (Figure 11).

3.5. Histopathological Evaluation. Histological examinations by light microscopy were performed for the healthy group (negative control) of the liver, kidney, and spleen section. In the kidney, several renal corpuscles were present in the cortical parenchyma of the kidney as well as it contained the proximal and distal renal tubule (X200) (Figure 12). While the portal tracts appear extending from the central vein to the periphery of the hepatic lobules (X100) (Figure 8). In addition, the spleen appears in a normal structure, consisting of a thickened capsule of connective tissue which consisting of the red pulp and the white pulp. In the central region, a wealthy area with $\mathrm{T}$ cells, also B cell important for follicles surrounded by a periarterial lymphoid sheath, the white pulp was collected around the artery surrounded by basic follicles rich in B cells. In the area around the red and white pulp, they were isolated by peripheral sinuses implanted in a layer of lymphocytes (X100) (Figure 12).
Moreover, the parasite did not demonstrate any clear effect on the kidney in the infected untreated control group, and all its tissues were appeared normal; nevertheless, the effect of the parasite appeared on both the spleen and liver, which appeared in hepatic parenchyma due to chronic granulomatous injuries. Injuries were formed by several Schistosoma haematobium eggs that contain mature miracidia, which contain many epithelioid cells, plasma cells, eosinophils, macrophages, and chronic inflammatory cells in the form of lymphocytes that formed a granuloma with a severe area of fibrosis (Figure 13). In the spleen, the boundaries between the red and white pulp began to disappear due to the cause of the appearance of the eggs surrounded by the inflammatory cellular response. A small number of spleen cells were evaluated. The sinusoidal spaces were big and most of the cells were darkly stained.

Histological liver sections treated with Origanum majorana, Ziziphus spina-christi, and Salvia fruticosa appeared temperate diffuse infiltration of liver parenchyma by chronic inflammatory cells without watched eggs or zone fibrosis (Figures 14-16). They appeared nonattendance of fibrosis and bilharzial eggs with an important decrease of infiltration in liver parenchyma by the chronic inflammatory cells. Whereas, spleen sections display more or less devolution of egg, enclosed by infiltration of lympho-epithelioid cellular inflammatory cells.

\section{Discussion}

With the expanding publicity of medications based on aqueous or alcoholic extracts or any other organic dissolvent of 


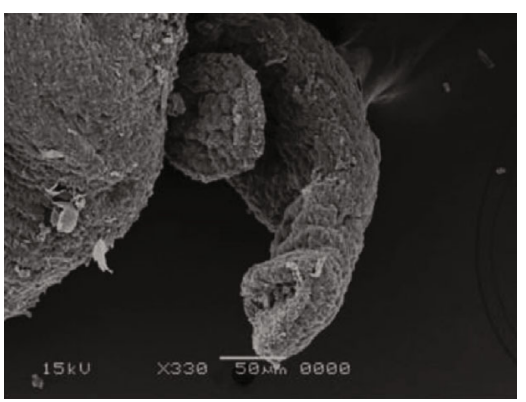

(a)

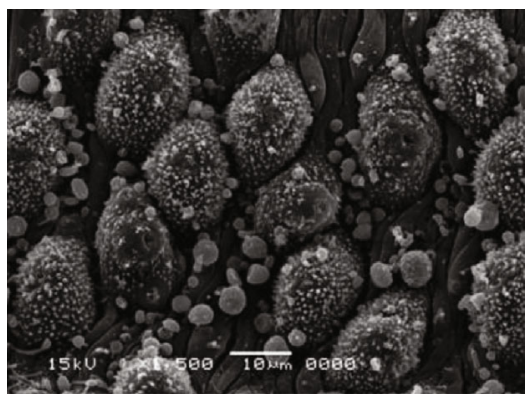

(b)

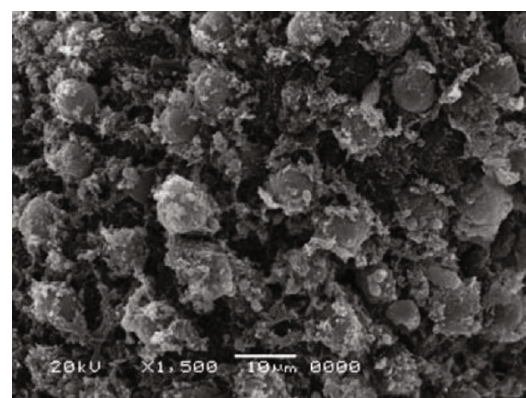

(c)

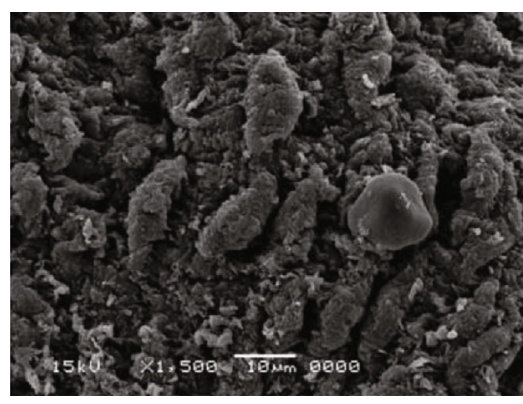

(d)

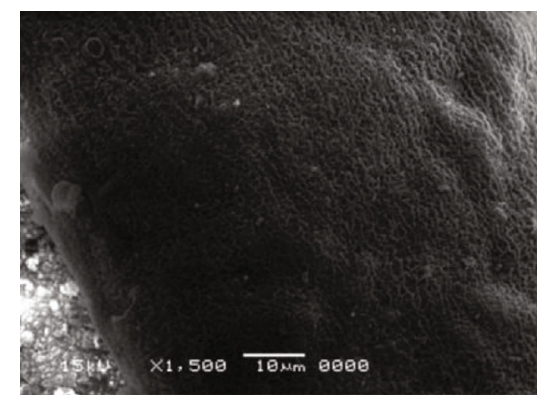

(e)

FIGURE 10: Scanning electron microscopy of S. haematobium (adult worms and schistosomula) after exposure to different concentrations of Ziziphus spina-christi. (a) Destroyed sucker. (b, c, d) Dorsal surface of male showing tegumental exfoliation with damage and exfoliation of spines and tubercles. (e) Schistosomula.

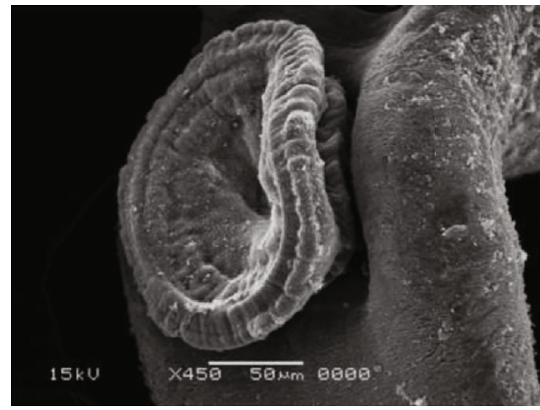

(a)

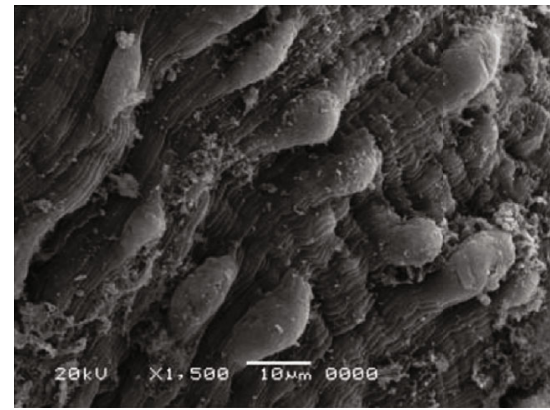

(b)

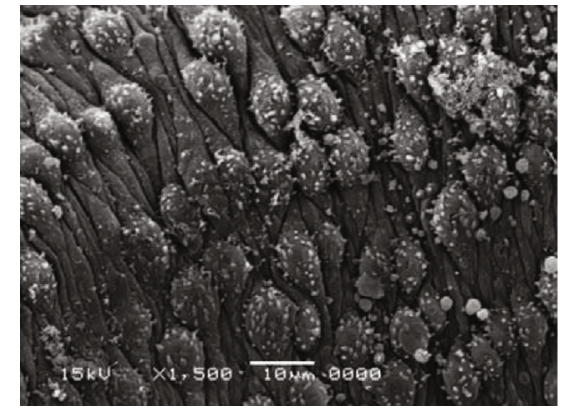

(c)

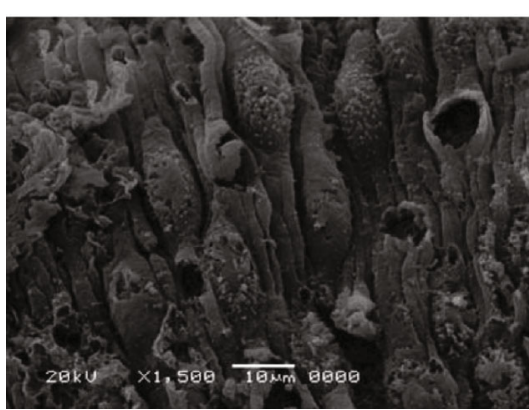

(d)

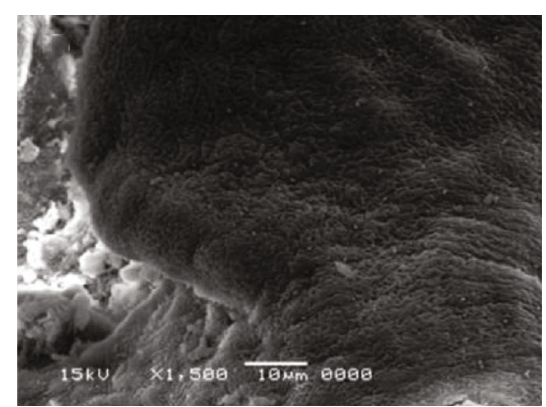

(e)

FIGURE 11: Scanning electron microscopy of S. haematobium (adult worms and schistosomula) after exposure to different concentrations of Salvia fruticosa. (a) Destroyed sucker. (b, c, d) Dorsal surface of male showing tegumental exfoliation with damage and exfoliation of spines and tubercles. (e) Schistosomula.

natural therapeutic plant extracts, the current study is planned to assess the antischistosomal influence of Origanum majorana, Ziziphus spina-christi, and Salvia fruticosa aqueous extract in the golden hamster experimentally infected with $S$. haematobium in comparison with the present utilized PZQ in patent and prepatent stages of the disease. 


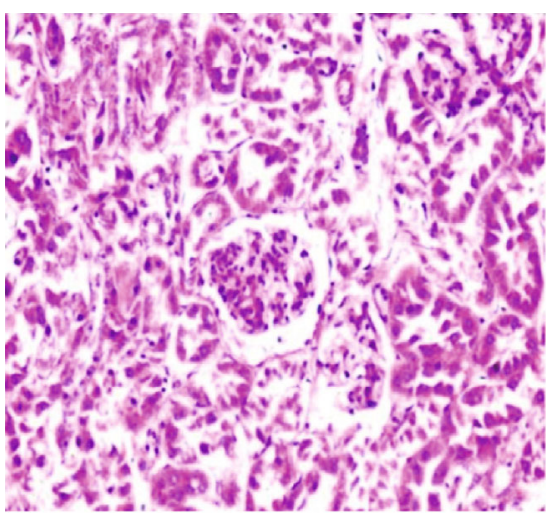

(a)

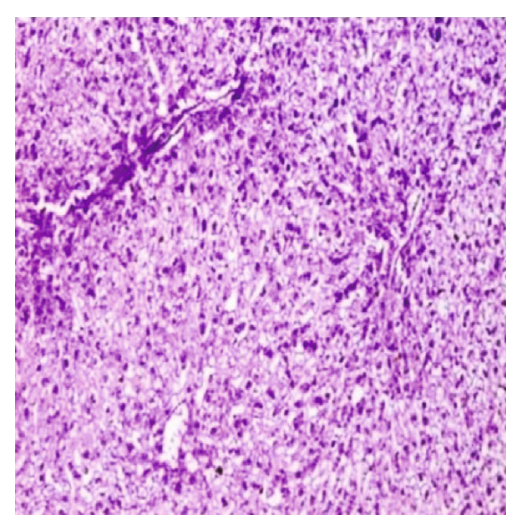

(b)

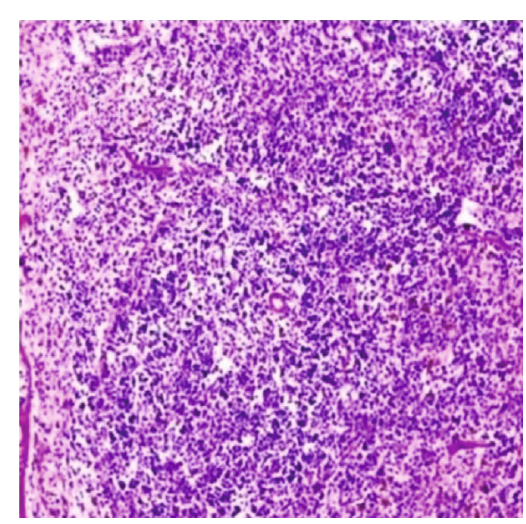

(c)

FIGURE 12: Histological section staining with hematoxylin and eosin for a healthy control (negative control). (a) Normal cortical structure in kidney control $(\times 200)$. (b) Normal hepatic lobular architecture in liver control $(\times 100)$. (c) Normal architecture in spleen control $(\times 100)$.

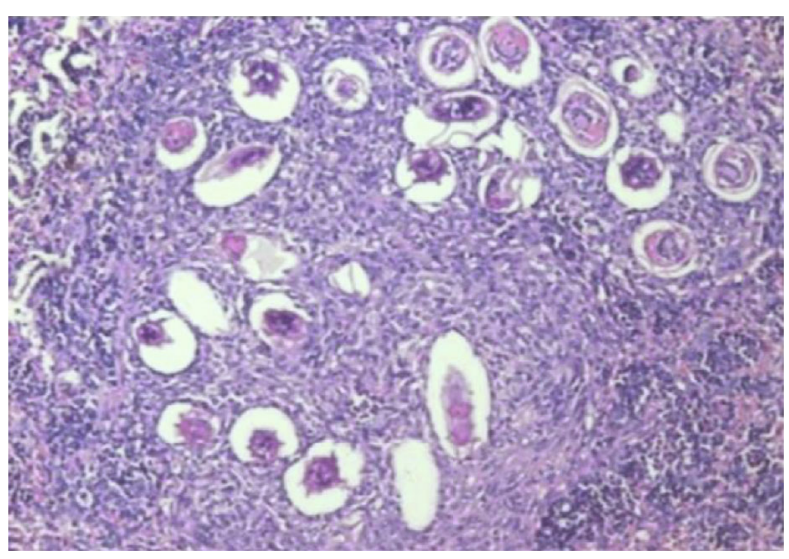

(a)

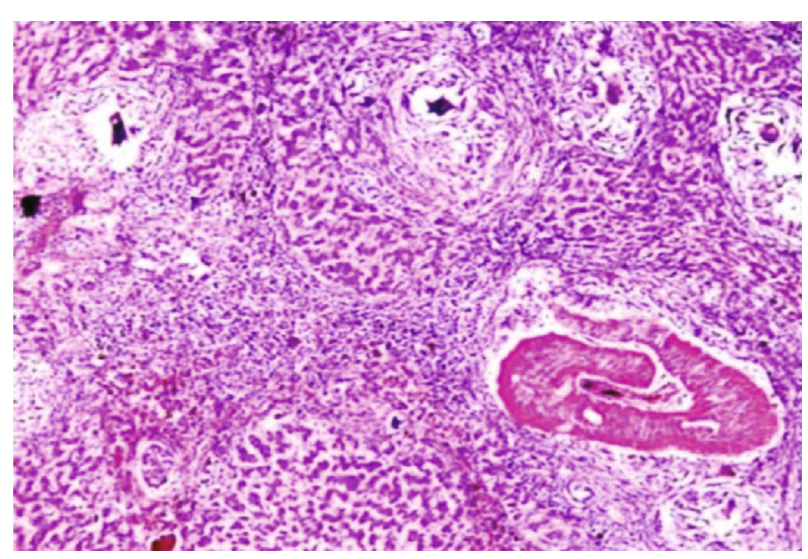

(b)

Figure 13: Histological section staining with hematoxylin and eosin for infected untreated control. (a) Aggregate of deposited ova of Schistosoma in spleen, enclosed by lympho-epithelioid tissue reaction $(\times 200)$. (b) A worm affect inside a portal vein and multiple egg granulomas in liver $(\times 100)$.

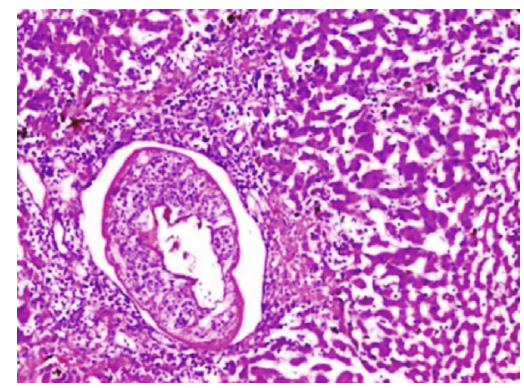

(a)

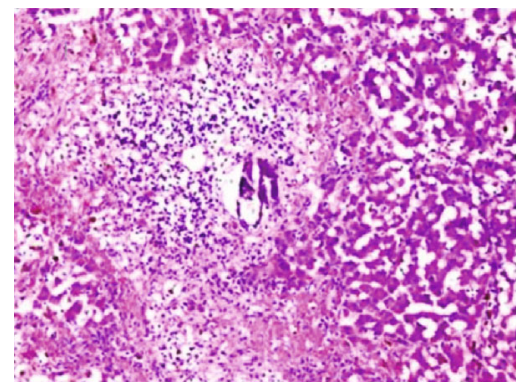

(b)

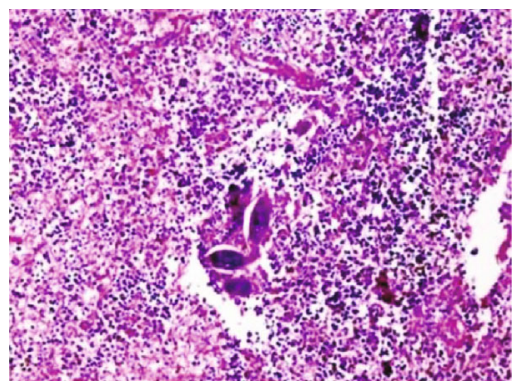

(c)

FIGURE 14: Histological section staining with H\&E of infected treated with $600 \mathrm{mg} / \mathrm{kg}$ Origanum majorana group. (a) Liver showing worm inside portal vein radical with moderate inflammatory changes within the hepatic lobule. (b) Liver showing intralobular ova enclosed by dense inflammatory cellular reaction and focal necrosis. (c) Some ova surrounded by inflammatory cellular reaction in the spleen $(\times 200)$.

The aqueous extracts of Origanum majorana, Ziziphus spina-christi, and Salvia fruticosa were chosen to avoid the high toxicity of organic dissolvents such as chloroform, methanol, dichloromethane, and acetone because water is a safe, nontoxic widespread dissolvent to living cells [34].
In the current study, different concentrations of the impact of Origanum majorana, Ziziphus spina-christi, and Salvia fruticosa aqueous extracts against Egyptian strain of Schistosoma (S. haematobium) were assessed in vitro and in vivo in the experimentally infected hamster. The study 


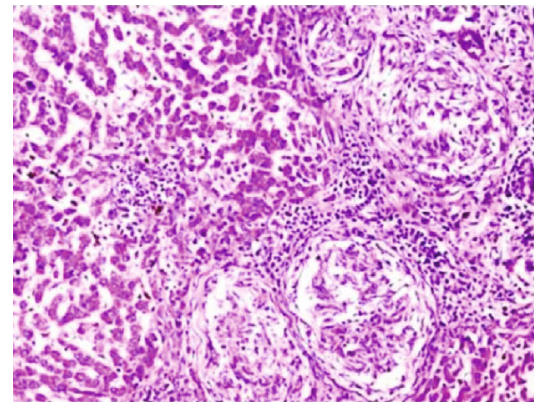

(a)

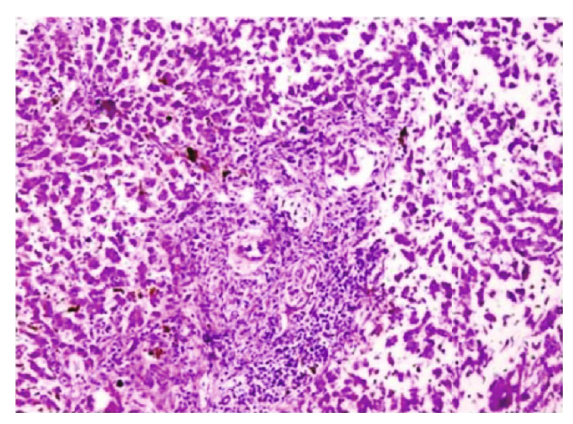

(b)

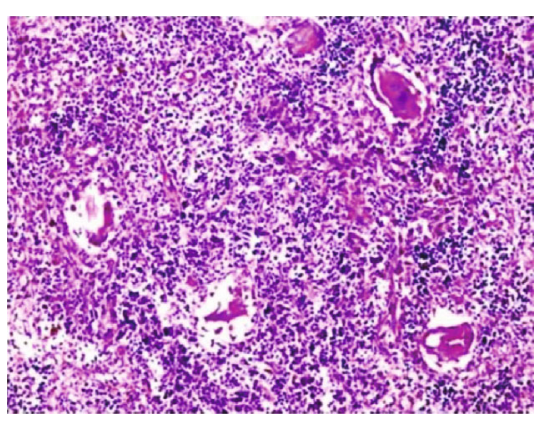

(c)

FiguRE 15: Histological section staining with H\&E of infected treated with $600 \mathrm{mg} / \mathrm{kg}$ Ziziphus spina-christi group. (a) Many lymphoepithelioid granulomas in the liver. (b) Amalgamated ova granulomas in the liver. (c) Many fresh deposited and degenerated egg in the spleen $(\times 200)$.

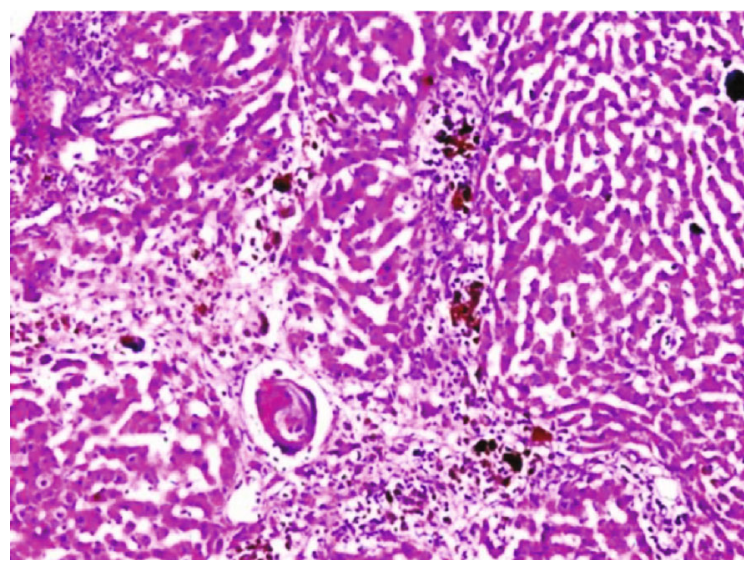

(a)

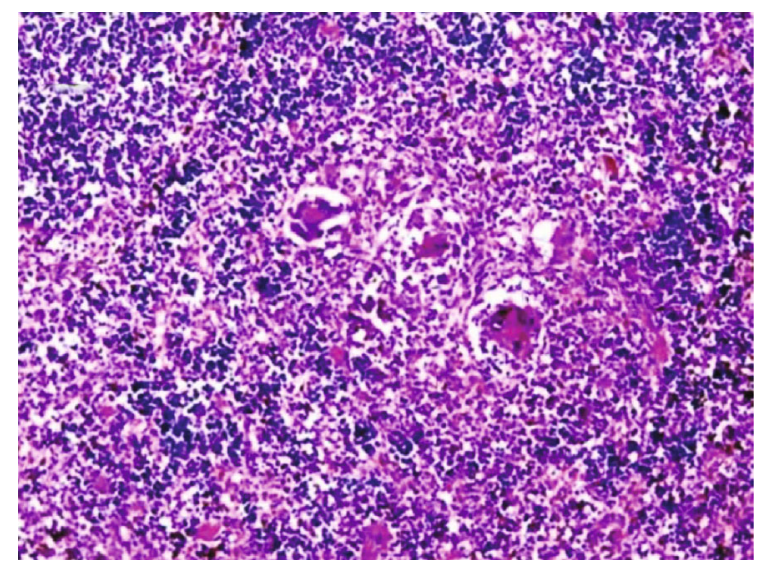

(b)

FIGURE 16: Histological section staining with H\&E of infected treated with $800 \mathrm{mg} / \mathrm{kg}$ Salvia fruticosa group. (a) Degenerated ova with mild infiltration of the hepatic lobule by mononuclear inflammatory cells in the liver. (b) Some degenerated ova, enclosed by lympho-epithelioid cellular inflammatory cellular infiltration $(\times 200)$.

was the primary one that examined the effectiveness of Origanum majorana, Ziziphus spina-christi, and Salvia fruticosa against $S$. haematobium. Additionally, as a step to begin with, in vitro studies of antischistosome carry out on the adult stage and schistosomule.

The current in vitro study has been confirmed the antischistosomal efficacy of Origanum majorana, Ziziphus spina-christi, and Salvia fruticosa extract on S. haematobium adult stage (survival time, motility, mating, and modifications of tegument) at different concentrations of 500, 250, $125,62.5$, and $31.25 \mu \mathrm{g} / \mathrm{ml}$.

The effects of dose-dependent were watched, the most efficient one with a concentration of $500 \mu \mathrm{g} / \mathrm{ml}$ begin in a shorter incubation period. All extracts that were examined caused the unpairing of couple worms, moderate constriction, decrease in motility, and loss of motion leading to the parasite's death most of the time, in a study accomplished by Noel [35], clarified the disability-related with significant neuromodulators or neurotransmitters such as acetylcholine, dopamine, and/or serotonin [35].

Origanum majorana and Ziziphus spina-christi extract were more effective mating inhibitors than Salvia fruticosa extracts. In vitro, Origanum majorana and Ziziphus spina- christi extract of $(500 \mathrm{mg} / \mathrm{kg})$ were efficient as PZQ. Previously, studies by Pica-Mattoccia and Cioli [36] had stated the PZQ impact on the adult worms, caused permanent contractions whenever the adult worms were uncovered to concentrations of 0.1 and $1 \mu \mathrm{g} / \mathrm{ml}$. Though, PZQ was known to cause a speedy calcium flow taken after by contraction, loss of motion, and tegument demolition.

The optical inverted microscopy utilizes did not permit the description of tegumental changes displayed in the parasite; in the present study, a specific examination with SEM (scanning electron microscopy) was used to assess the sample tegumental harm after treatment in vitro. Many authors had been used SEM in arrange to explain the mechanisms of drug/compound activity utilized in the treatment of schistosomiasis test $[37,38]$.

The changes caused by aqueous extracts treatment of Origanum majorana, Ziziphus spina-christi, and Salvia fruticosa regard to harm in suckers, oral and acetabularin of both female and male schistosomes. Adult worms investigation with SEM showed that the treatment caused an integument broad peeling, particularly in the dorsal area, occurring from the exposure of these surface antigens. Besides, blebs were visual on the male worms treatment exposed to Origanum 
majorana, Ziziphus spina-christi, and Salvia fruticosa extracts. Similar results were reported by de Oliveira [39], as the Schistosoma mansoni worms that were treated with an aqueous fracture extract and also dichloromethane crude of Baccharis trimera, showed strong efficacy in killing adult worms. The sarcoplasmic membrane of schistosomiasis is the first defense wall. Changes in the body wall of adult worms may result after treatment with medicinal plant extracts with antischistosomiasis activity through their membranes, allowing the sarcoplasmic membrane of the adult worms to be exposed to antigens. Younes [40] prepared an ethanolic extract of the edible pomegranate plant, which showed efficacy on the adult worms of Schistosoma mansoni. Kang [41] demonstrated that the mice were dosed with hederacolchiside A1 fractional extract from Pulsatilla chinensis in their studies on Schistosoma mansoni and Schistosoma japonicum, where the results showed that the worms were killed after 11 days in mice, and the pathological parameters in mice infected with Schistosoma japonicum began to improve.

In the current study, The Origanum majorana, Ziziphus spina-christi, and Salvia fruticosa extracts in vivo antischistosomal effect on $S$. haematobium infected golden hamster were assessed concerning histopathological changes (schistosomal granulomas, hepatic inflammation effective, and a number of egg in the tissues of the liver), spleen and kidney. The examined extracts appeared dose-dependent decrease in both granuloma number and diameter, egg number in spleen and liver tissues, both, fibrosis and inflammatory infiltration compared to infected control (the untreated control groups).

The efficiency of Origanum majorana and Ziziphus spina-christi extracts was more than Salvia fruticosa in decreasing granuloma diameter and number. An important decrease appeared in hepatic fibrosis and inflammatory liver infiltration by using Origanum majorana extract comparative PZQ. Ziziphus spina-christi appeared temperate activity, whereas Salvia fruticosa extract appeared less conspicuous effect. Origanum majorana extract at the higher treatment appeared significant result compared to PZQ in decreasing diameter and granuloma number. The decrease of granulomatous inflammation volume indicated an anti-inflammatory influence of the utilized extracts. Concerning the eggs of Schistosoma in infected hamster tissues, changing reaction was with different extracts, where Salvia fruticosa extract decreased the egg number in the spleen and liver tissues at the high concentration, while eggs were found damage or not found in liver and spleen tissues with Origanum majorana at the same dosage and Ziziphus spina-christi extract at the lower dosage compared to PZQ. The results acquired from the past experiments in vivo and in vitro performed by the other authors were similar, utilizing Piper tuberculatum separated component, 8-hydroxyquinoline derivatives from Baccharis trimera, Artemisia annua, and pomegranate that have shown effectiveness against schistosome [42-46].

\section{Data Availability}

The data used to support the results of this study were deposited in a repository [Twumasi et al., 2020 doi:10.1371/journal.pntd.0008919; Alves et al., doi:10.1017/ S003118202000181X; Yones et al., 2016 10.1155/2016/ 2872708].

\section{Conflicts of Interest}

The authors declare that they have no conflicts of interest.

\section{Acknowledgments}

This work was supported by the Deanship of Scientific Research (DSR), King Abdulaziz University, Jeddah, under grant No. (130-228 - D1440). The authors, therefore, gratefully acknowledge the DSR technical and financial support.

\section{References}

[1] P. Steinmann, J. Keiser, R. Bos, M. Tanner, and J. Utzinger, "Schistosomiasis and water resources development: systematic review, meta-analysis, and estimates of people at risk," The Lancet Infectious Diseases, vol. 6, no. 7, pp. 411-425, 2006.

[2] B. Gryseels, K. Polman, J. Clerinx, and L. Kestens, "Human schistosomiasis," The Lancet, vol. 368, no. 9541, pp. 11061118, 2006.

[3] World Health Organization (WHO), "Schistosomiasis fact sheet," 2014, https://www.who.int/mediacentre/factsheets/ fs115/en.

[4] World Health Organization (WHO), "Schistosomiasis fact sheet," 2019, https://www.who.int/news-room/fact-sheets/ detail/schistosomiasis.

[5] M. Ruffer, "Note on the presence of "Bilharzia haematobia" in Egyptian mummies of the twentieth dynasty [1250-1000 B.C.]," British Medical Journal, vol. 1, no. 2557, p. 16, 1910.

[6] G. Contis and A. David, "The epidemiology of bilharzia in ancient Egypt: 5000 years of schistosomiasis," Parasitology Today, vol. 12, no. 7, pp. 253-255, 1996.

[7] A. David, "Disease in Egyptian mummies: the contribution of new technologies," The Lancet, vol. 349, no. 9067, pp. 17601763, 1997.

[8] T. El Khoby, N. Galal, and A. Fenwick, "The USAID/government of Egypt's schistosomiasis research project (SRP)," Parasitology Today, vol. 14, no. 3, pp. 92-96, 1998.

[9] R. M. Barakat, "Epidemiology of schistosomiasis in Egypt: travel through time," Journal of Advanced Research, vol. 4, no. 5, pp. 425-432, 2013.

[10] A. Fenwick, "Praziquantel: do we need another antischistosoma treatment?," Future Medicinal Chemistry, vol. 7, no. 6, pp. 677-680, 2015.

[11] E. M. Tekwu, W. K. Anyan, D. Boamah et al., "Mechanically produced schistosomula as a higher-throughput tools for phenotypic pre-screening in drug sensitivity assays: current research and future trends," Biomarker Research, vol. 4, no. $1,2016$.

[12] D. Cioli, L. Pica-Mattoccia, A. Basso, and A. Guidi, "Schistosomiasis control: praziquantel forever?," Molecular and Biochemical Parasitology, vol. 195, no. 1, pp. 23-29, 2014.

[13] J. de Moraes, C. Nascimento, L. F. Yamaguchi, M. J. Kato, and E. Nakano, "Schistosoma mansoni: in vitro schistosomicidal activity and tegumental alterations induced by piplartine on schistosomula," Experimental Parasitology, vol. 132, no. 2, pp. 222-227, 2012. 
[14] O. Kayser, A. F. Kiderlen, and S. L. Croft, "Natural products as antiparasitic drugs," Parasitology Research, vol. 90, pp. S55S62, 2003.

[15] S. Tagboto and S. Townson, "Antiparasitic properties of medicinal plants and other naturally occurring products," Advances in Parasitology, vol. 50, pp. 199-295, 2001.

[16] P. Mølgaard, S. B. Nielsen, D. E. Rasmussen, R. B. Drummond, N. Makaza, and J. Andreassen, "Anthelmintic screening of Zimbabwean plants traditionally used against schistosomiasis," Journal of Ethnopharmacology, vol. 74, no. 3, pp. 257264, 2001.

[17] C. G. Braguine, E. S. Costa, L. G. Magalhães et al., "Schistosomicidal evaluation of Zanthoxylum naranjillo and its isolated compounds against Schistosoma mansoni adult worms," Zeitschrift für Naturforschung. Section C, vol. 64, no. 11-12, pp. 793-797, 2010.

[18] L. G. Magalhães, C. B. Machado, E. R. Morais et al., "In vitro schistosomicidal activity of curcumin against Schistosoma mansoni adult worms," Parasitology Research, vol. 104, no. 5, pp. 1197-1201, 2009.

[19] J. de Moraes, C. Nascimento, P. O. Lopes et al., "Schistosoma mansoni: in vitro schistosomicidal activity of piplartine," Experimental Parasitology, vol. 127, no. 2, pp. 357-364, 2011.

[20] F. Yousif, G. Wassel, L. Boulos et al., "Contribution to in vitro screening of Egyptian plants for schistosomicidal activity," Pharmaceutical Biology, vol. 50, no. 6, pp. 732-739, 2012.

[21] J. de Moraes, "Antischistosomal natural compounds: present challenges for new drug screens," in Current Topics in Tropical Medicine, D. A. Rodriguez-Morales, Ed., InTech Open, Rijeka, Croatia, 2012.

[22] M. A. Ekpo and P. C. Etim, "Antimicrobial activity of ethanolic and aqueous extracts of Sida acuta on microorganisms from skin infections," Journal of Medicinal Plant Research, vol. 3, no. 9, pp. 621-624, 2009.

[23] T. Mosmann, "Rapid colorimetric assay for cellular growth and survival: application to proliferation and cytotoxicity assays," Journal of Immunological Methods, vol. 65, no. 1-2, pp. 55-63, 1983.

[24] S. R. Smithers and R. J. Terry, "The infection of laboratory hosts with cercariae of Schistosoma mansoni and the recovery of the adult worms," Parasitology, vol. 55, no. 4, pp. 695-700, 1965.

[25] M. A. Stirewalt and C. H. Dorsey, "Schistosoma manonsi: cercarial penetration of host epidermis at the ultrastructural level," Experimental Parasitology, vol. 35, no. 1, pp. 1-15, 1974.

[26] Z. H. Fahmy, A. M. El-Shennawy, W. El-Komy, E. Ali, and S. S. Abdel Hamid, "Potential antiparasitic activity of pomegranate extracts against shistosomules and mature worms of Schistosoma mansoni: in vitro and in vivo study," Australian Journal of Basic and Applied Sciences, vol. 3, no. 4, pp. 4634-4643, 2009.

[27] S. H. Xiao, J. Keiser, J. Chollet et al., "In vitro and in vivo activities of synthetic trioxolanes against major human schistosome species," Antimicrobial Agents and Chemotherapy, vol. 51, no. 4, pp. 1440-1445, 2007.

[28] J. D. Moraes, A. A. Almeida, M. R. Brito et al., "Anthelmintic activity of the natural compound (+)-limonene epoxide against Schistosoma mansoni," Planta Medica, vol. 79, no. 34, pp. 253-258, 2013.

[29] A. M. Glauert, "Fixation, dehydration and embedding of biological specimens," in Practical Methods in Electron Micros- copy, A. Glauert, Ed., pp. 77-163, Elsevier, Amsterdam Oxford, 1974.

[30] M. Baker, K. Johnson, and I. Roberts, "Passive arguments raised," Linguistic Inquiry, vol. 20, no. 2, pp. 219-251, 1989.

[31] M. J. Farah, C. Rabinowitz, G. E. Quinn, and G. T. Liu, "Early commitment of neural substrates for face recognition," Cognitive Neuropsychology, vol. 17, no. 1-3, pp. 117-123, 2000.

[32] J. I. Rader, P. Delmonte, and M. W. Trucksess, "Recent studies on selected botanical dietary supplement ingredients," Analytical and Bioanalytical Chemistry, vol. 389, no. 1, pp. 27-35, 2007.

[33] G. W. Snedecor and W. G. Cochran, Statistical Methods, Iowa State University Press, Ames, 7th edition, 1980.

[34] K. G. Kinuthia, O. C. Anjili, W. E. Kabiru, M. E. Kigondu, M. J. Ingonga, and K. N. Gikonyo, "Toxicity and efficacy of aqueous crude extracts from Allium sativum, Callistemon citrinus and Moringa stenopetala against L. major," Kabarak Journal of Research \& Innovation, vol. 3, pp. 9-20, 2015.

[35] F. Noel, "Sistema neuromuscular e controle da motilidade do verme adulto," in Schistosoma mansoni \& Esquistossomose: Uma Vis $\sim$ ao Multidisciplinar, O. S. Carvalho, P. M. Z. Coelho, and H. L. Lenzi, Eds., pp. 207-244, FIOCRUZ, Rio de Janeiro, Brazil, 2008.

[36] L. Pica-Mattoccia and D. Cioli, "Sex- and stage-related sensitivity of Schistosoma mansoni to in vivo and in vitro praziquantel treatment," International Journal for Parasitology, vol. 34, no. 4, pp. 527-533, 2004.

[37] R. N. de Oliveira, V. L. G. Rehder, A. S. S. Oliveira, V. D. L. S. Jeraldo, A. X. Linhares, and S. M. Allegretti, "Anthelmintic activity in vitro and in vivo of Baccharis trimera (Less) DC against immature and adult worms of Schistosoma mansoni," Experimental Parasitology, vol. 139, no. 1, pp. 63-72, 2014.

[38] M. F. Abou El-Nour and Y. Fadladdin, "Antischistosomal activity of Zingiber officinale, Piper nigrum, and Coriandrum sativum aqueous plant extracts on hamster infected with Schistosoma mansoni," Journal of Parasitology Research, vol. 2021, Article ID 6628787, 21 pages, 2021.

[39] R. N. de Oliveira, V. L. G. Rehder, A. S. S. Oliveira et al., "Schistosoma mansoni: In vitro schistosomicidal activity of essential oil of Baccharis trimera (less) DC," Experimental Parasitology, vol. 132, no. 2, pp. 135-143, 2012.

[40] D. A. Yones, D. M. Badary, H. M. B. Sayed, S. A. H. Bayoumi, A. A. Khalifa, and A. M. el-Moghazy, "Comparative evaluation of anthelmintic activity of edible and ornamental pomegranate ethanolic extracts against Schistosoma mansoni," BioMed Research International, vol. 2016, Article ID 2872708, 15 pages, 2016.

[41] N. Kang, W. Shen, H. Gao et al., "Antischistosomal properties of hederacolchiside A1 isolated from Pulsatilla chinensis," Molecules, vol. 23, no. 6, article ???, 2018.

[42] R. El Ridi, H. Tallima, M. Salah et al., "Efficacy and mechanism of action of arachidonic acid in the treatment of hamsters infected with Schistosoma mansoni or Schistosoma haematobium," International Journal of Antimicrobial Agents, vol. 39, no. 3, pp. 232-239, 2012.

[43] T. Manneck, Y. Haggenmüller, and J. Keiser, "Morphological effects and tegumental alterations induced by mefloquine on schistosomula and adult flukes of Schistosoma mansoni," Parasitology, vol. 137, no. 1, pp. 85-98, 2010.

[44] G. Allam, A. F. Eweas, and A. S. A. Abuelsaad, "In vivo schistosomicidal activity of three novels 8-hydroxyquinoline 
derivatives against adult and immature worms of Schistosoma mansoni," Parasitology Research, vol. 112, no. 9, pp. 31373149, 2013.

[45] R. S. Almeer, M. F. El-Khadragy, S. Abdelhabib, and A. E. Abdel Moneim, "Ziziphus Spina-Christi Leaf Extract Ameliorates Schistosomiasis Liver Granuloma, Fibrosis, and Oxidative Stress through Downregulation of Fibrinogenic Signaling in Mice," PLoS One, vol. 13, no. 10, article e0204923, 2018.

[46] M. F. el-Khadragy, E. M. al-Olayan, M. I. Y. Elmallah, A. M. Alharbi, H. M. Yehia, and A. E. Abdel Moneim, "Probiotics and yogurt modulate oxidative stress and fibrosis in livers of Schistosoma mansoni-infected mice," BMC Complementary and Alternative Medicine, vol. 19, no. 1, p. 3, 2019. 